Rev. Elet. em Gestão, Educação e Tecnologia Ambiental (e-ISSN: 2236-1170)

\title{
A EDUCAÇÃO COMO INSTRUMENTO DE PROTEÇÃO AMBIENTAL
}

\author{
Arismar Maneia', Vera Cuzzuol² \\ 'Professor da FAACZ, Mestre em Tecnologia Ambiental pela Faculdade de Aracruz, ES. Mestre em Ciências da \\ Educação, Pós graduado em Filosofia, Graduado em Ciências, Graduando em Ciências \\ Sociais.(arismarmaneia12@hotmail.com) \\ ${ }^{2}$ Diretora Geral, Mestra em Tecnologia Ambiental pela Faculdade de Aracruz, ES, Pós graduada em Gestão de Pessoas, \\ Graduada em Pedagogia (Administração Escolar).(vcuzzuol@gmail.com)
}

\section{RESUMO}

Este trabalho reporta-se a uma ação reflexiva sobre a educação no ensino formal como instrumento de transformação de comportamento do educando institucional que se preocupa com as questões sobre a proteção ao meio ambiente. A história da humanidade conduz o universo ambiental às degradações, aos danos ambientais causados pelo avanço desenfreado das novas tecnologias nas diferentes atividades humanas sem a sensibilidade de fazer uso do meio ambiente e, consequentemente, sem que haja uma constante ameaça socioambiental. As ideias abordadas sustentam uma postura importante na difusão sobre a Educação Ambiental em relação ao papel da educação crítica e reflexiva. Aqui se pretende demonstrar que todo esforço só terá valor quando aperfeiçoarmos conhecimento e traçarmos objetivos para uma consciência de cidadania ambiental.

PALAVRAS-CHAVE: Educação, Educação Ambiental, Meio Ambiente.

\section{ABSTRACT}

This work relates to a reflexive action on education in formal education as an instrument of transformation of institutional schooling behavior that concerns itself with issues about the protection of the environment. The history of mankind drives the universe to environmental degradation, environmental damage caused by the rampant advancement of new technologies in different human activities without the sensitivity to make use of the environment and, consequently, without there being a constant environmental threat. The ideas addressed important posture support a broadcast about the environmental education in relation to the role of education critical and reflective. Here if you want to demonstrate that every effort will only have value when traçarmos goals for improving knowledge and awareness of environmental citizenship.

KEYWORDS: Education, Environmental Education, Environment. 
Rev. Elet. em Gestão, Educação e Tecnologia Ambiental (e-ISSN: 2236-1170)

\section{INTRODUÇÃO}

Em sentido amplo, a Educação Ambiental deve permear a educação, entendida como uma ação evolutiva que propicia aos cidadãos uma visão crítica, reflexiva e participativa de sua existência na sociedade como sujeitos num constante processo de conhecimento e amadurecimento humano.

O trabalho embasou-se em uma pesquisa bibliográfica de autores nacionais, de obras literárias e da Carta Magna brasileira, adotando como foco o conceito de educação prevista na Lei Maior, sua relação com o processo ensino e aprendizagem, o meio ambiente, enquanto definição, proteção jurídica e o dano ambiental e finalizando com a percepção subjetiva da educação ambiental, seus fundamentos cognitivos com objetivo de despertar uma visão crítica e legal ao educandos que se sensibilizam com a questão socioambiental. Aponta-se aqui a relação entre a viabilidade de utilizar, a partir da educação formal, um meio de auxiliar a questão ambiental.

A reflexão e a prática educativa possibilitam um engajamento possível entre os educandos que procuram fundamentação teórica com intuito de fazer acontecer a educação ambiental nas relações sociais. É interessante salientar a relevância da educação ambiental que se constitui uma forma abrangente de educação, que se propõe a atingir o cidadão através de um processo pedagógico participativo e permanente, no qual o bastante não é a teoria, mas sim a predominância da prática, procurando incutir no educando uma consciência cristalizada da proteção ambiental.

\section{EDUCAÇÃO PARA UMA AÇÃO REFLEXIVA}

\subsection{EDUCAÇÃO E CIDADANIA}

O tema Educação Ambiental na formação educativa deve promover a preparação e a reflexão do educando no sentido formal e levar aos futuros cidadãos uma qualidade de vida com respeito à natureza e a si mesmos, resgatando princípios elementares da convivência humana.

Conceituar educação nas suas mais variadas vertentes é um grande desafio. Educar vai além do ato formal de transmissão de conhecimento à informalidade do indivíduo no contexto em que está inserido.

Para Lanfredi (2007, p. 130), a educação:

[...] está relacionada à formação de personalidade, feita pela ação dos adultos, que exercem influência sobre as crianças e os jovens, estimulando-os a fazer bom uso de suas potencialidades latentes, senão também a adotar e vivenciar os valores dentro de uma determinada escala.

O indivíduo, em sua essência, é um ser dotado de liberdade. Como um ser que possui capacidade de optar entre o bem e o mal, de escolher sua escala de valores, torna-se sujeito e agente de sua própria história. A educação vem para auxiliá-lo a hierarquizar seus valores e fazer correto o uso de sua liberdade.

A educação é uma ação que passa nas várias gerações futuras e que auxilia na compreensão sobre atos comportamentais em relação ao universo da sociedade humana, e traz consigo valores que despertam no homem buscas e sentidos de valores e princípios comportamentais. Veja que "Investindo em educação, estamos investindo no homem" (LANFREDI, 2007) e que "Educar para não punir", princípio da sabedoria grega, é perfeitamente cabível na 


\section{Rev. Elet. em Gestão, Educação e Tecnologia Ambiental (e-ISSN: 2236-1170)}

realidade brasileira. A fragmentação dos conhecimentos a respeito do meio em que se vive é que vem ocasionando uma educação punitiva em detrimento da falta de uma educação corretiva.

A educação está sempre em constante evolução, matérias entram e saem dos currículos escolares conforme as necessidades do mundo. Pois essa é a função da educação formal: preparar o cidadão para enfrentar todas as situações decorrentes da postura individual.

Daí se conclui que a causa eficiente da educação

[...] é a comunicação educativa entre quem ensina e quem aprende. Equivale a dizer que no processo educativo há interação entre pessoas que ensinam e pessoas que aprendem, tanto na maneira assistemática como no caso da família, da escola, da igreja, como de maneira assistemática, no caso de ação do ambiente sobre o indivíduo (LOUREIRO, 2002, p. 48).

O que se observa é que a educação apresenta-se como uma maneira de o homem ser visto no mundo em seu papel social, propondo modelos de comportamentos, de atitudes (LANFREDI, 2007).

\subsection{EDUCAÇÃO E AÇÃO PARA APRENDIZAGEM}

É importante frisar que educação é um processo amplo, contínuo e complexo. Com isso, a aprendizagem e o ensino não se esgotam na aquisição de conhecimentos, pelo contrário, a educação deve ultrapassar a abordagem informativa para, assim, garantir a formação ser sujeitos críticos preparados para a convivência num processo social e cultural.

A educação não pode ser vislumbrada somente na teoria. O processo de aprendizagem só se concretiza com a efetivação da prática atrelada à difusão do conhecimento. Vejamos o que nos relata Tozoni-Reis $(2004$, p.79) a respeito do processo educativo.

O ser humano é o único ser vivo que passa completa e constantemente pelo processo educativo, ele é um ser inacabado. Ao nascer, não traz, além de sua base biológica, os instrumentos necessários e adequados à sua sobrevivência como espécie. [...] A educação surge como um fenômeno propriamente humano; os indivíduos são produto e produtores dos processos educativos. [...] A educação pode ser um instrumento de humanização, pode produzir humanidade, produzir sujeitos plenos. Pode produzir mas nem sempre o faz, isto é, ao nascer o ser humano traz a possibilidade de vir-a-ser, a possibilidade de ser produzido e de produzir a si e aos outros.

Os Parâmetros Curriculares Nacionais (MEC, 1997) preceituam que para ocorrer uma aprendizagem significativa é necessária

[...] a disponibilidade para o envolvimento do aluno na aprendizagem, o empenho em estabelecer relações entre o que já sabe e o que está aprendendo, em usar os instrumentos adequados que conhece e dispõe para alcançar a maior compreensão possível. Essa aprendizagem exige uma ousadia para se colocar problemas, buscar soluções e experimentar novos caminhos, de maneira totalmente diferente da aprendizagem mecânica, na qual o aluno limita seu esforço apenas em memorizar ou estabelecer relações diretas e superficiais.

A educação não é constituída apenas pela transmissão de conhecimento, mas traz, atrelada a esses ensinamentos, toda a realidade na qual o ato educativo se realiza: as pessoas, as condições 
Rev. Elet. em Gestão, Educação e Tecnologia Ambiental (e-ISSN: 2236-1170)

físicas e a interação entre o professor e aluno, num entrave denominado processo ensinoaprendizagem (FIGUEIREDO, 2001).

\title{
1.3 A EDUCAÇÃO NA ESFERA CONSTITUCIONAL
}

A Carta Magna brasileira, a Constituição Federal de 1988, aborda a educação no Capítulo III, seção I, dos art. 205 a 214. Vejamos:

Art. 205. A educação, direito de todos e dever do Estado e da família, será promovida e incentivada com a colaboração da sociedade, visando ao pleno desenvolvimento da pessoa, seu preparo para o exercício da cidadania e sua qualificação para o trabalho.

E, ainda, o Art. 206:

\author{
O ensino será ministrado com base nos seguintes princípios: \\ I - igualdade de condições para o acesso e permanência na escola; \\ II - liberdade de aprender, ensinar, pesquisar e divulgar o pensamento, a arte e o saber; \\ III - pluralismo de idéias e de concepções pedagógicas e coexistência de instituições \\ públicas e privadas do ensino; \\ IV - gratuidade do ensino público em estabelecimentos oficiais; \\ V - valorização dos profissionais do ensino, garantidos, na forma da lei, planos de carreira \\ para o magistério público, com piso salarial profissional e ingresso exclusivamente por \\ concurso público de provas e títulos; \\ $\mathrm{VI}$ - gestão democrática do ensino público, na forma da lei; \\ VII - garantia de padrão de qualidade.
}

Embora algumas conquistas educacionais sejam inquestionáveis, a realidade existente ainda é bastante deficitária, visto que uma grande parcela da população brasileira encontra-se impedida de ter acesso à educação por fatores sociais, morais e até culturais.

\section{A EDUCAÇÃO AMBIENTAL E O MEIO AMBIENTE}

\subsection{REFLEXÃO SOBRE O MEIO AMBIENTE}

Dentre todas as espécies o homem, como ser vivo, é o único dotado de pensamentos. Graças ao seu processo de evolução, ou seja, através da adaptação ao meio, e pela herança biológica, conseguiu estabelecer sua existência e evolução social, que orientam o processo de domínio sobre os outros seres e a capacidade de exploração do meio ambiente, discriminando e discernindo o útil do inútil, o bem do mal, o preterido do preferido. Essa somatória de heranças é que o torna diferente dos outros seres do planeta.

Como entender a expressão "estar-no-mundo" sem entender o que é "meio ambiente"? As duas expressões reportam-se a uma profunda busca no âmbito da consciência, enquanto seres pensantes e dotados de discernimento, de que somos os agentes transformadores únicos e capazes de garantir a absoluta existência e permanência da espécie humana na Terra.

Para Sirvinskas (2007, p. 28,29), o termo meio ambiente é redundante, pois consiste na repetição de ideias com o mesmo sentido. Vejamos: 
Rev. Elet. em Gestão, Educação e Tecnologia Ambiental (e-ISSN: 2236-1170)

[...] meio é aquilo que está no centro de alguma coisa. Ambiente indica o lugar ou a área onde habitam seres vivos. Assim na palavra "ambiente" está também inserido o conceito de meio. [...] Em outras palavras, meio ambiente é o lugar onde habitam os seres vivos. É o habitat dos seres vivos. Esse habitat (meio físico) interage com os seres vivos (meio biótico), formando um conjunto harmonioso de condições essenciais para a existência da vida como um todo.

A Lei Federal 6.981/81, que instituiu a Política Nacional do Meio Ambiente, definiu meio ambiente como

[...] conjunto de condições, leis, influências e interações de ordem física, química e biológica que permite, abriga e rege a vida e todas as suas formas (art. $3 \circ$ ํㅣ), considerando o ambiente como um patrimônio público a ser necessariamente assegurado e protegido, tendo em vista o uso coletivo (art. 2ㅇ, I) (LANFREDI, 2007,p.57).

\subsection{A PROTEÇÃO JURÍDICA DO MEIO AMBIENTE}

A autonomia do direito caracteriza-se pelo fato de possuir seus próprios regimes jurídicos, objetivos e princípios. Não ocorre diferente do direito ambiental, em específico. Muitos conceitos, normas e princípios são extraídos dos diversos ramos das normas jurídicas já existentes (DE JESUS JUNIOR, 2001).

O fenômeno de agressão ao meio ambiente vem desde os primórdios dos tempos. Há décadas a destruição do meio ambiente, em detrimento do crescimento econômico, era considerada uma consequência normal. Com isso, inexistia uma consciência social sobre a problemática ambiental.

Dentre as legislações brasileiras que disciplinam e protegem o meio ambiente podemos citar a Lei 6.938/81 - que instituiu a Política Nacional do Meio Ambiente no Brasil, a Lei 7.347/85 que instituiu a Ação Civil Pública, completada pela Lei 9.605/98 - sobre os crimes ambientais, bem como a Lei 9.795/99, que dispõe sobre a Educação Ambiental, e a Constituição Federal, no art. 225, que preceitua:

Art. 225. Todos têm direito ao meio ambiente ecologicamente equilibrado, bem de uso comum do povo e essencial à sadia qualidade de vida, impondo-se ao poder público e à coletividade o dever de defendê-lo e preservá-lo para as presentes e futuras gerações.

O tratamento jurídico à causa ambiental iniciou seu processo a partir dos grandes desastres ecológicos internacionais provocados pelos navios petroleiros causaram reações mundiais. Daí surgem as convenções, estabelecendo o "princípio da responsabilidade" e os demais princípios vigentes nas leis ambientais (LANFREDI, 2007).

Segundo Sirvinskas (2007, p. 33):

[...] princípio é a base, o alicerce, o início de alguma coisa. É a regra fundamental de uma crise. Há quem entenda que o princípio é fonte normativa. São inúmeros os princípios ambientais arrolados pelos doutrinadores, a saber: o princípio do dever de todos os Estados de proteger o ambiente; princípio da obrigatoriedade de informações e da consulta prévia; princípio da precaução; princípio do aproveitamento eqüitativo, ótimo e razoável dos recursos naturais; princípio do poluidor-pagador; princípio da igualdade; [...] princípio da proteção do meio ambiente em relação aos interesses privados; princípio da indisponibilidade do interesse público na proteção do meio ambiente; princípio da 
Rev. Elet. em Gestão, Educação e Tecnologia Ambiental (e-ISSN: 2236-1170)

obrigatoriedade da intervenção estatal; princípio da prevenção; princípio do desenvolvimento sustentável; princípio da proteção da biodiversidade [...].

O que se observa é que os princípios ambientais, ora citados, e na sua maioria decorrentes de ordenamentos jurídicos, tendem a proteger toda espécie de vida do planeta, promovendo "a sadia qualidade de vida", conforme determinado na Constituição.

\subsection{DANO AMBIENTAL X PROTEÇÃO AO MEIO AMBIENTE}

O planeta clama por socorro. Furacões devastam as Américas, tsunamis varrem a Ásia deixando rastro de destruição e morte. Na Europa, a cada ano novos recordes de temperatura são quebrados, geleiras derretem na Antártica e praias vão virando mar em toda a costa brasileira.

É em virtude dessa realidade, na qual o homem corre risco de se tornar um animal em extinção, que medidas para tentar salvar o mundo em que vivemos estão ocorrendo em todo o território mundial. Governos assinam convenções, declarações e protocolos internacionais além de criarem normas internas visando à diminuição dos danos ambientais e à recuperação do ecossistema.

Toda atividade humana é, direta ou indiretamente, responsável por modificações abrangentes no meio ambiente. Este é um sistema formado por complexas e recíprocas interações entre os elementos naturais e os seres vivos. Com isso, a proteção ambiental tem em vista os reflexos destas ações sobre outros seres humanos.

Segundo as normas brasileiras vigentes, os responsáveis por todos os atos ilícitos que gerarem consequências negativas e prejudicarem a terceiros devem reparar ou ressarcir os danos causados.

Sirvinskas (2007, p. 151) conceitua dano como:

[...] toda lesão a um bem jurídico tutelado. Dano Ambiental, por sua vez, é toda agressão contra o meio ambiente causada por atividade econômica potencialmente poluidora, por ato comissivo praticado por qualquer pessoa ou por omissão voluntária decorrente de negligência. Esse dano, por seu turno, pode ser economicamente reparado ou ressarcido. Aquele decorre da obrigação de reparar a lesão causada a terceiro, procurando recuperar ou recompor o bem danificado. Como nem todo bem é recuperável, nesse caso, será fixado um valor indenizatório pelo dano causado ao bem difuso.

Segundo Mezzomo (2004, p. 69)

[...] ao operador jurídico interessa o conceito jurídico de dano, e não é todo o dano ambiental que demanda responsabilidade jurídica. Sim, porque se qualquer dano ambiental fosse implicar em responsabilização, a maior parte das atividades corriqueiras dos seres humanos se tornaria inviável.

As organizações não governamentais, cada vez mais influentes e presentes, criam mecanismos de defesa da natureza e, consequentemente, ajudam a proteger o sistema climático e ecológico.

Sirvinskas (2007, p. 4) afirma que “[...] as agressões ao meio ambiente são as mais diversas e, para protegê-lo, faz-se necessário conscientizar o homem por meio do conhecimento da relação homem versus ambiente". 
Rev. Elet. em Gestão, Educação e Tecnologia Ambiental (e-ISSN: 2236-1170)

\section{A EDUCAÇÃO AMBIENTAL}

\subsection{PERCEPÇÃO SUBJETIVA DO SIGNIFICADO DE EDUCAÇÃO AMBIENTAL}

A sociedade atual vive tempos de desordem. Um mundo desgastado por crises em suas bases familiares, crises de valores, de princípios morais e éticos, enfim, crise no sentido mínimo da palavra. A fragmentação advinda dessas "crises sociais" faz majorar a violência, a marginalidade e a fome, levando o homem a atemorizar-se num "mundo social" separado do "mundo natural" (DE JESUS JUNIOR, 2001).

Falar de educação ambiental sem compreender o que significa, no sentido mínimo da palavra, o termo meio ambiente é um ato impossível, melhor dizendo, não há entendimento/compreensão quando não se conhece aquilo que se pretende estudar desde o mais simples significado.

O art. 1 ㅇ da Lei 9.795/99 define educação ambiental como:

[...] processos por meio dos quais o indivíduo e coletividades constroem valores sociais, conhecimentos, habilidades, atitudes e competências voltadas para a conservação do meio ambiente, bem de uso comum do povo, essencial à sadia qualidade de vida e sua sustentabilidade.

E, ainda, o art. 2ㅇda Lei 9.795/99 preceitua que a educação ambiental "é um componente essencial e permanente da educação nacional, devendo estar presente, de forma articulada, em todos os níveis e modalidades do processo educativo, em caráter formal e não formal".

Segundo Tozoni-Reis (2004, p. 70), educação ambiental foi lembrada como:

[...] a única maneira possível de evitar a destruição do ambiente, como uma postura em relação à natureza, como busca de uma convivência boa com a natureza, ou ainda, como conservação da qualidade de vida e como contemplação da natureza. Então a educação ambiental está voltada para que os sujeitos se reconheçam como integrantes do ambiente, é a busca de uma nova conduta [...].

A educação ambiental não foi, até o momento, incorporada em todos os níveis de ensino no sistema educacional brasileiro e apresenta-se apenas como temas transversais nos Parâmetros Curriculares Nacionais. Infelizmente, os parâmetros não designam ações possíveis para os planos de ação nem, tampouco, treinamentos aos docentes (FIGUEIREDO, 2001).

Luis Paulo Sirvinskas (2007, p.28), em sua obra Manual do Direito Ambiental, coloca em xeque-mate as expressões "conservação" e "preservação". Etimologicamente, têm o mesmo sentido, mas, em seus estudos, trabalha os termos, sendo "conservar é permitir exploração econômica dos recursos naturais de maneira racional e sem causar desperdício", enquanto "preservar é a proibição da exploração econômica dos recursos naturais".

A Educação Ambiental na rede brasileira de ensino é trabalhada de forma interdisciplinar, devendo cada disciplina analisar a questão ambiental no enfoque local e regional. Para atingir um público bem abrangente é necessária a utilização de vários meios, dentre os quais destacamos não só a escola, na formação formal, mas as rádios, tvs, a imprensa, como formação não-formal.

\subsection{FUNDAMENTOS DA EDUCAÇÃO AMBIENTAL}




\section{Rev. Elet. em Gestão, Educação e Tecnologia Ambiental (e-ISSN: 2236-1170)}

A Educação Ambiental está fundamentada em estudos que na sua essência geraram trabalhos com finalidades de possibilitar a formação de uma opinião pública esclarecida e uma conduta responsável por parte dos indivíduos, das comunidades, tendo como escopo uma política séria e comprometida com o meio ambiente (LANFREDI, 2007).

Conhecedores de vários tratados, fóruns nacionais e internacionais, convenções que balizaram as diretrizes que vão ao encontro de assegurar a proteção ao meio ambiente, podemos citar a Declaração de Estocolmo, de 1972, a Carta de Belgrado, que resultou num encontro da UNESCO em 1975, bem como a Conferência de Tbilisi, Geórgia, em 1977, que garantiu nas suas diretrizes a importância da perspectiva interdisciplinar (LANFREDI, 2007).

No que concerne à educação, surgiram outros encontros internacionais e nacionais que marcaram época, como nos relata Lanfredi (2007, p. 141):

[...] em Jomtien, Tailândia (1990), Toronto, Canadá (1992) e Istambul, Turquia (1993). Desenvolveu-se, após, uma série de Conferências das Nações Unidas - iniciadas em 1992, com a do Rio de Janeiro (Meio Ambiente e Desenvolvimento) - que ocorreram no Cairo, Egito (População), em 1994, Copenhague, Dinamarca (Desenvolvimento Social), em 1995, e Istambul, Turquia (Assentamentos Humanos) em 1996. (...) Por fim, de 08. a 12.03.1997, realizou-se em Tessalônica, na Grécia, pela UNESCO, mais uma Conferência Internacional sobre o tema Educação e Conscientização Pública para a Sustentabilidade, em que se fizeram presentes representantes de 84 países.

No Brasil, a Lei 9.795, de 27.04.1999, que criou a Política Nacional de Educação Ambiental, é o documento balizador, de maior importância, que regulamenta a EA em toda a esfera do ensino brasileiro.

\subsection{O OBJETO DA EDUCAÇÃO AMBIENTAL}

No cenário nacional e mundial e que se reflete no universo do estudo realizado, há uma crescente contraposição (não hegemônica) à tradicional lógica dominante da expansão de um modelo de sociedade (urbano-industrial). A expansão desse modelo se dá por meio do processo de modernização conservadora, baseado em paradigmas desenvolvimentistas, calcado na prevalência das necessidades econômicas sobre as necessidades socioambientais, e que traz como consequência a crise ambiental que já se instalou em toda parte.

Tratando-se de educação ambiental e, com efeito, a Constituição Federal, no art. 225, preceitua que "todos têm direito ao meio ambiente ecologicamente equilibrado, essencial à sadia qualidade de vida", o objeto da EA é, segundo Lanfredi (2007, p. 164):

O objeto imediato da tutela é a qualidade do meio ambiente, enquanto o mediato é a saúde, o bem-estar e a segurança da população, sintetizando na expressão qualidade de vida, valendo observar, no entanto, que a legislação ambiental toma como objeto da proteção elementos setoriais constitutivos do meio ambiente, como a qualidade do solo, da flora, do ar, da água.

Percebe-se, neste estudo, que o objeto da EA é a qualidade de vida na relação do homem com o meio ambiental, tendo como escopo as palavras preservar, recuperar, melhorar e transformar posturas, tudo com um objetivo-fim que é a busca incessante da melhoraria da sobrevivência das espécies no planeta, nave mãe. 
Rev. Elet. em Gestão, Educação e Tecnologia Ambiental (e-ISSN: 2236-1170)

\section{CONSIDERAÇÕES FINAIS}

"É pela educação ambiental que se cria uma consciência social sobre o problema ecológico". Essa frase, de Geraldo Ferreira Lanfredi, em sua obra "Política Ambiental”, conclui com muita convicção o estudo realizado sobre o tema ora proposto.

Muito embora esteja ocorrendo grande avanço na questão ecológica, ainda há pouco investimento e preocupação quanto à Educação Ambiental. Somente através da educação é possível formar cidadãos socialmente responsáveis e conscientes, capazes de mudar a realidade em nossa volta.

Sendo assim a educação é o grande instrumento de prevenção aos danos causados ao meio ambiente é a educação. Logo, a educação Ambiental é entendida como um dos mecanismos mais privilegiados para alcançarmos a eficiência e eficácia na conscientização da prevenção e conservação da natureza.

Entender de consciência ecológica é entender os sentidos das palavras preservação e proteção. A necessidade de proteger o meio em que vivemos nasce quando somos ameaçados por alguma agressão que prejudique diretamente o status quo do homem.

A preocupação com o processo de proteção emergente é oriunda de que os jovens de amanhã possam chegar a sua plenitude com uma formação voltada para uma visão crítica da sua realidade local e planetária, em que seu envolvimento às causas sociais e ambientais seja uma constante, uma realidade, não apenas algo momentâneo.

Observou-se, durante este estudo, que o primeiro passo para promover uma conscientização pública ecológica é através da regulamentação das normas ambientais pelas leis federais, estaduais e até na esfera municipal. No Brasil, isso é um ato muito recente, já que somente na década de 90 o art. 225 da Constituição de 1988 foi regulamentado pela Lei 9.795/99, que dispôs sobre a Educação Ambiental e instituiu a Política Nacional de Educação Ambiental.

Finalizando, percebe-se que a Educação Ambiental é o grande instrumento vital na formação do cidadão de hoje. É impossível viver hoje sem, de alguma maneira, prejudicar o meio ambiente. A evolução foi tão rápida e tão grande que o homem não abdica de certos objetos da vida cotidiana, e que são provenientes da natureza, em detrimento de uma consciência ecológica. O que pode ocorrer é a diminuição do consumo excessivo de matérias oriundas da natureza ou, ainda, descobrir fórmulas menos poluentes do meio ambiente.

\section{REFERÊNCIAS}

BRASIL. Secretaria de Educação Fundamental. Parâmetros Curriculares Nacionais. Brasília: MEC/SEF, 1997.

. Constituição da República Federativa do Brasil. Brasília, 1988.

DE JESUS JÚNIOR, Guilhardes. Direito ambiental: espaço de construção da cidadania. Jus Navigandi, Vitória da Conquista, 2001. Disponível em: <http://jus2.uol.com.br/doutrina/texto.asp?id=4378>. Acesso em: 15 fev. 2012. 
Rev. Elet. em Gestão, Educação e Tecnologia Ambiental (e-ISSN: 2236-1170)

FIGUEIREDO, Rodolfo Antônio de. A Lei no 9.795/99 reveste-se de importância para os educadores ambientais brasileiros?. Jus Navigandi, Teresina, ano 6, n. 52, nov. 2001. Disponível em: <http://jus2.uol.com.br/doutrina/texto.asp?id=2312>. Disponível em: 20 jan. 2012.

LANFREDI, Geraldo Ferreira. Política ambiental: busca de efetividade de seus instrumentos. 2. ed. São Paulo: Editora Revista dos Tribunais, 2007.

LOUREIRO, Janete Ribeiro. Didática e currículo. Aracruz: FACHA, 2002.

MEZZOMO, Marcelo Colombelli. Responsabilidade ambiental. Jus Navigandi. Teresina. Ano 9, n. 523, 12 dez. 2004. Disponível em: <http://jus2.uol.com.br/doutrina/texto.asp?id=5981>. Acesso em: 20 fev. 2012.

SIRVINSKAS, Luis Paulo. Manual do direito ambiental. 5. ed. São Paulo: Saraiva, 2007.

TOZONI-REIS, Marília Freitas de Campos. Educação ambiental: natureza, razão e história. São Paulo: Autores Associados, 2004. 